\title{
Sex differences in heritable and environmental risk of abdominal obesity: family-based study and case- control study of rural adults in China
}

\section{Songcheng $\mathrm{Yu}$}

Zhengzhou University

\section{Yinhua Feng}

Zhengzhou University

Chenling Qu

Henan University of Technology

\section{Xing Li}

Zhengzhou University

Wenqian Huo

Zhengzhou University

\section{Zhenxing Mao}

Zhengzhou University

\section{Changying Chen}

Zhengzhou University

Chongjian Wang

Zhengzhou University

Wenjie Li ( $\square$ zzuliwenjie@126.com )

Zhengzhou University https://orcid.org/0000-0002-1768-1178

\section{Research}

Keywords: abdominal obesity, sex differences, heritable and environmental risk, physical activity, familybased study

Posted Date: April 19th, 2021

DOI: https://doi.org/10.21203/rs.3.rs-413365/v1

License: (1) (1) This work is licensed under a Creative Commons Attribution 4.0 International License.

Read Full License 


\section{Abstract}

Background: Abdominal obesity (AO) has shown a dramatic increase trend in the past decades. But there were few studies on sex differences in the risk of AO, especially the heritable risk. This study aimed to investigate the sex differences of $\mathrm{AO}$ risk in China rural areas.

Methods: A family-based study coupled with the Henan Rural Cohort was carried out, including 1,533 people and 39,259 people, respectively. Questionnaires were applied in including included demographics, dietary intake and physical activity. Combined family-based study with the Henan Rural Cohort, sex differences in heritable risk of $A O$ was analyzed among rural people. Chi-square test was applied to study the heritable risk of $\mathrm{AO}$. Environmental factors for $\mathrm{AO}$ were assessed in couple case-control study. Logistic regression analysis was carried out to assess the association of lifestyles with $\mathrm{AO}$.

Results: Women had higher risk to develop AO than men in Henan Rural Cohort (OR: 3.070, 95\% Cl: 2.943, $3.203, P<0.001)$. The female first-degree relatives were more susceptible to AO than those in the Henan Rural Cohort (OR: 1.854, 95\% Cl: 1.318, 2.608, $P<0.001)$. Moreover, female offspring had higher risk to develop AO than male offspring when their mothers suffered from $A O(O R: 1.797,95 \% \mathrm{Cl}$. 1.111, 2.907, $P=0.016)$, and this risk increased if their grandmothers suffered from $A O(O R: 6.750,95 \%$ Cl: 1.667 , 27.336, $P=0.007)$. In addition, low physical activity increased the risk to develop AO for women when compared with their husbands (OR: 2.253, 95\% Cl: 1.283, 3.957, $P=0.005)$.

Conclusion: This study indicated females are heritably susceptible to AO than men, especially for those who have maternal family history and reinforce the benefits of increasing physical activity for protecting females from suffering from $\mathrm{AO}$. Proactive action based on maternal family history is a cost-effective strategy for the prevention of $\mathrm{AO}$, although larger family-based studies are required to verify the conclusion.

\section{Background}

Obesity, defined by body mass index (BMI), is remarkably associated with many health risk factors and raised mortality risk from chronic diseases including diabetes mellitus, cardiovascular disease, dyslipidemia and metabolic syndrome.[1-3] However, the distribution of adipose tissue in the body is different. Abdominal obesity (AO) caused by excessive accumulation of abdominal fat, assessed by waist circumference (WC). It was reported that the body fat content of AO with the same BMI was higher than that of overall obesity, which was significantly related to metabolic diseases.[4, 5] Mounting evidence suggested that people with AO may be more vulnerable to metabolic diseases.[6, 7] In South Korea, AO was the second major factor in the growth of the prevalence of metabolic syndrome in the past decade.[8] A similar situation prevailed in China, where AO was significantly associated with hypertension, stroke and cardiovascular metabolism risk.[9]

Population-based studies have shown that genetic factors play an important role in the development of AO. A study of 100 pairs of healthy twins from the UK showed that the heritability of WC was 0.74 .[10] In 
China, studies based on offspring-parents suggested that the heritability of WC was 0.51 .[11] Besides, heritability estimates in families with type 2 diabetes mellitus showed that the heritability of WC was 0.63, which further indicated that WC was associated with increased risk of metabolic diseases.[12] However, there were few studies on sex differences in the risk of $A O$, especially the heritable risk. Additional information on sex differences in the risk of $A O$ helps to control the prevalence of metabolic diseases and has important public health implications.

In addition, a large proportion of the population still live in rural areas with limited access to health but high burden of metabolic disorders. Thus, a family-based study was carried out in rural China. Comparing with the AO prevalence in Henan Rural Cohort study, the AO prevalence among the first-degree relatives of probands could be applied to speculate the heritable risk. Furthermore, it could provide further evidence by comparison of the $\mathrm{AO}$ prevalence between female and male offspring of $\mathrm{AO}$ cases. Besides, casecontrol couples could be employed to investigate the sex differences of environmental risk factors of AO. This study will provide more reliable evidence for sex-specific prevention and help reduce the burden of metabolic disorders in rural areas.

\section{Methods}

\section{Study subjects}

In this family-based study 1,533 participants from 499 extended families including $130 \mathrm{AO}$ probands and their 359 first-degree relatives were recruited. From them, 433 offspring of $A O$ cases were selected to assess the heritable risk. On the other hand, 178 case-control couples (40 husband-case and 138 wifecase) out of 377 couples $(N=754)$ was included to investigate the environmental risk factor of $A O$ (Fig. 1). All the participants living in rural area of Zhengzhou city or Jiaozuo city in Henan Province, China.

In this study, 39,259 subjects from Henan Rural Cohort were recruited from five rural regions of Henan Province, China. The registration number of Henan Rural Cohort was ChiCTR-00C-15006699, detail information of which was available at the website (http://www.chictr.org.cn/showproj.aspx?proj=11375), as well as the introduction article we published previously.[13]

This study complied with the Declaration of Helsinki. The Life Science Ethics Review Committee of Zhengzhou University had reviewed and approved the protocol. All the subjects participated in this study had signed an informed consent.

\section{Definition Of Abdominal Obesity}

WC was measured from the midpoint line between the lowest point of the rib and the upper edge of the iliac crest using non-elastic tape. According to the recommendation of Working Group on Obesity in China (WGOC), the appropriate cut-off point for AO for adults in China was defined as WC $\geq 85 \mathrm{~cm}$ for men and $\geq 80 \mathrm{~cm}$ for women.[14] 


\section{Information Collection By Face-to-face Interview}

A face-to-face interview with standardized questionnaire was conducted for all the participated individuals in this family-based study by well-trained investigators. The information collected included demographics, dietary intake and physical activity.

Combined with the Chinese Residents Dietary Guidelines and local people dietary habits, food frequency questionnaire was applied to collect dietary intake information. According to the Chinese Food Composition Table, fat intake was figured with multiplying the fat of detailed portion size in each food item by the frequency, divided into $<50, \geq 50 \mathrm{~g} /$ day, and vegetables intake were classified as $<50, \geq 50$ g/day.[15]

The short version of the international physical activity questionnaires (IPAQ) was employed to collect the physical activity information. By showing illustration cards of different physical activities with description, the investigators recorded the self-report physical activity within the last 7 days for all the participants. Based on the IPAQ scoring protocol version 2.0 (http://www.ipaq.ki), physical activity was divided into three levels of low, moderate and high.

\section{Statistical analysis}

In order to reveal the sex differences of heritable and environmental risk factors for $\mathrm{AO}$, the strategy of statistical analysis was as follows. First, chi-square test was applied to investigate the heritable risk on AO by comparing the prevalence of $\mathrm{AO}$ between the first-degree relatives and the Henan Rural Cohort. Second, the heritable risk was verified by comparing the prevalence of $\mathrm{AO}$ between male and female offspring with chi-square test. Third, logistic regression analysis was carried out to assess the association of dietary intake and physical activity with AO. SPSS 21.0 (IBM SPSS, New York, US) was applied to conduct all the statistical analysis. A value of $P$ less than 0.05 was considered statistically significant.

\section{Results}

\section{Structural characteristic of the family-based study and the couple case-control study}

In the family-based study, 130 probands and their 359 first-degree relatives were included, i.e. 130 fathers, 130 mothers, 67 siblings, and 32 offspring. In the couple study, 377 couples were included, i.e. 63 couples without AO, 40 couples with AO for husband, 138 couples with $A O$ for wife, and 136 couples with $A O$ for both husband and wife. There was no distribution difference between the four different couple types $(P=$ $0.061)$. Then the 40 couples with $A O$ for husband and the 138 couples with $A O$ for wife were applied as case-control studies (Model 1 and Model 2 in Table 4, respectively) to investigate the associations of diet and physical activity with AO.

\section{Association Between Sex And Abdominal Obesity}


39,259 subjects and 1,533 subjects were recruited to investigate the association between sex and $A O$ in the Henan Rural Cohort and the family-based study (Table 1). The result for the Henan Rural Cohort suggested that women had higher risk to develop AO than men (OR: 3.070, 95\% Cl: 2.943, 3.203, $P<$ $0.001)$. This significant association between sex and $A O$ was also observed in the family-based study (OR: 2.617, 95\% Cl: 2.127, 3.221, $P<0.001$ ).

Table 1

Association between sex and abdominal obesity in the family-based study and the Henan Rural Cohort

\begin{tabular}{|c|c|c|c|c|c|}
\hline & & $\begin{array}{l}\text { None- } \\
\text { AO }\end{array}$ & AO & $O R(95 \% C l)$ & $P$ \\
\hline \multirow[t]{3}{*}{$\begin{array}{l}\text { The Henan Rural Cohort }(\mathrm{N}= \\
\text { 39259) }\end{array}$} & & & & $\begin{array}{l}3.070(2.943- \\
3.203)\end{array}$ & ¿ $0.001 *$ \\
\hline & Male & 10065 & 5425 & & \\
\hline & Female & 8953 & 14816 & & \\
\hline \multirow[t]{3}{*}{ The family-based study $(\mathrm{N}=1533)$} & & & & $\begin{array}{l}2.617(2.127- \\
3.221)\end{array}$ & ¿.001* \\
\hline & Male & 418 & 330 & & \\
\hline & Female & 256 & 529 & & \\
\hline
\end{tabular}

\section{Prevalence comparison of abdominal obesity between the first-degree relatives and the Henan Rural Cohort}

The prevalence of $\mathrm{AO}$ in the Henan Rural Cohort and the first-degree relatives were $51.6 \%$ and $57.4 \%$, respectively (Table 2). Compared with the subjects in the Henan Rural Cohort, the first-degree relatives were at a higher risk to develop AO $(O R: 1.265,95 \% \mathrm{Cl}$ : 1.025, 1.561, $P=0.028)$. In the subgroup analysis, the female first-degree relatives were more susceptible to $A O$ than those in the Henan Rural Cohort ( $O R$ : $1.854,95 \% \mathrm{Cl}: 1.318,2.608, P<0.001)$. Instead, this phenomenon was not observed in the male firstdegree relatives $(P=0.216)$. 
Table 2

The prevalence comparison of abdominal obesity between the first-degree relatives and the Henan Rural Cohort

\begin{tabular}{|c|c|c|c|c|}
\hline & None-AO & $\mathrm{AO}$ & $O R(95 \% C l)$ & $P$ \\
\hline \multicolumn{5}{|l|}{ Total } \\
\hline \multirow[t]{2}{*}{ Henan Rural Cohort } & \multirow[t]{2}{*}{19018 (48.4) } & \multirow[t]{2}{*}{$20241(51.6)$} & 1.265 & \multirow[t]{2}{*}{$0.028 *$} \\
\hline & & & $(1.025-1.561)$ & \\
\hline first-degree relatives & $153(42.6)$ & $206(57.4)$ & & \\
\hline \multicolumn{5}{|l|}{ Male } \\
\hline \multirow[t]{2}{*}{ Henan Rural Cohort } & \multirow[t]{2}{*}{10065 (65.0) } & \multirow[t]{2}{*}{$5425(35.0)$} & 1.208 & \multirow[t]{2}{*}{0.216} \\
\hline & & & $(0.895-1.632)$ & \\
\hline first-degree relatives & $109(60.6)$ & $71(39.4)$ & & \\
\hline \multicolumn{5}{|l|}{ Female } \\
\hline \multirow[t]{2}{*}{ Henan Rural Cohort } & \multirow[t]{2}{*}{8953 (37.7) } & \multirow[t]{2}{*}{$14816(62.3)$} & 1.854 & \multirow[t]{2}{*}{$<0.001^{x}$} \\
\hline & & & $(1.318-2.608)$ & \\
\hline first-degree relatives & $44(24.6)$ & $135(75.4)$ & & \\
\hline
\end{tabular}

\section{Prevalence Comparison Of Abdominal Obesity Among Parents/grandparents-offspring}

The prevalence of $\mathrm{AO}$ was compared between male and female offspring with parents or grandparents with $\mathrm{AO}$ (Table 3). The results suggested that female offspring had a higher risk to develop $A O$ than male offspring when their mothers suffered from $A O(O R: 1.797,95 \% \mathrm{Cl} 1.111,2.907, P=0.016)$. Moreover, female individuals with a grandmother with $A O$ were at a much higher risk to develop $A O$ than males (OR: $6.750,95 \% \mathrm{Cl}$. 1.667, 27.336, $P=0.007)$. Instead, there was no significant difference for the prevalence of AO between male and female offspring with a father or grandfather with $\mathrm{AO}(P>0.05)$. 
Table 3

The prevalence comparison of abdominal obesity among male and female offspring

$\begin{array}{llll}\text { Offspring None-AO AO OR }(95 \% \mathrm{Cl}) & P\end{array}$

Father with $\mathrm{AO}$

$\begin{array}{lllll}\text { Male } & 35(58.3) & 25(41.7) & 0.884(0.364-2.145) & 0.785 \\ \text { Female } & 19(61.3) & 12(38.7) & & \end{array}$

Mother with AO

$\begin{array}{lllll}\text { Male } & 96(56.1) & 75(43.9) & 1.797(1.111-2.907) & \mathbf{0 . 0 1 6 *} \\ \text { Female } & 47(41.6) & 66(58.4) & & \end{array}$

Grandfather with AO

$\begin{array}{lllll}\text { Male } & 4(66.7) & 2(33.3) & 1.000(0.053-18.915) & 1.000 \\ \text { Female } & 2(66.6) & 1(33.3) & & \end{array}$

Grandmother with AO

$\begin{array}{lllll}\text { Male } & 27(87.1) & 4(12.9) & 6.750(1.667-27.336) & \mathbf{0 . 0 0 7 *} \\ \text { Female } & 9(50.0) & 9(50.0) & & \end{array}$

Note: Chi-square test was applied to investigate the prevalence difference between male and female offspring. AO: abdominal obesity. ${ }^{\star} P<0.05$.

\section{Environmental risk assessment for abdominal obesity in couple case-control study}

The associations between diet, physical activity, and $\mathrm{AO}$ were assessed by couple case-control study included couples in which one partner $\mathrm{AO}$ and the other was control (Table 4, placed at the end of manuscript). It was suggested that low physical activity would increase the risk to develop AO for women when compared with their husbands (OR: 2.253, 95\% Cl: 1.283, 3.957, $P=0.005)$. But physical activity was not significantly associated with male AO when wives were control $(P>0.05)$. On the other hand, higher fat intake was significantly associated with an increased risk of male AO (OR: $3.486,95 \% \mathrm{Cl}$. $1.113,10.920, P=0.032)$. In contrast, higher fat intake was a protective factor for female AO (OR: 0.420, $95 \%$ Cl: $0.213,0.830, P=0.012)$. 
Table 4

Environmental risk assessment for Abdominal Obesity in couple case-control study

\begin{tabular}{|c|c|c|c|c|c|}
\hline Variables & & Control & Case & OR $(95 \% C l)$ & $P$ \\
\hline \multicolumn{6}{|l|}{$\begin{array}{l}\text { Model 1-Husband with } \\
\text { AO }\end{array}$} \\
\hline Age (Years) & & $\begin{array}{l}47.7 \pm \\
14.9\end{array}$ & $\begin{array}{l}47.8 \pm \\
14.9\end{array}$ & $1.012(0.979-1.047)$ & 0.473 \\
\hline \multirow[t]{3}{*}{ Physical Activity (\%) } & $\mathrm{H}$ & $16(40.0)$ & $17(42.5)$ & Reference & \\
\hline & M & $7(17.5)$ & $6(15.0)$ & $0.602(0.152-2.390)$ & 0.471 \\
\hline & $\mathrm{L}$ & $17(42.5)$ & $17(42.5)$ & $0.994(0.367-2.694)$ & 0.990 \\
\hline \multirow[t]{2}{*}{ Vegetable intake (\%) } & $<500 \mathrm{~g} /$ day & $30(75.0)$ & $30(75.0)$ & $0.956(0.332-2.756)$ & 0.934 \\
\hline & $\begin{array}{l}\geq 500 \\
\text { g/day }\end{array}$ & $10(25.0)$ & $10(25.0)$ & & \\
\hline \multirow[t]{2}{*}{ Fat intake (\%) } & $<50 \mathrm{~g} /$ day & $32(80.0)$ & $24(60.0)$ & $\begin{array}{l}3.486(1.113- \\
10.920)\end{array}$ & $0.032 *$ \\
\hline & $\geq 50 \mathrm{~g} /$ day & $8(20.0)$ & $16(40.0)$ & & \\
\hline
\end{tabular}

Model 2-Wife with AO

\begin{tabular}{|c|c|c|c|c|c|}
\hline Age (Years) & & $\begin{array}{l}58.2 \pm \\
11.8\end{array}$ & $\begin{array}{l}57.4 \pm \\
11.6\end{array}$ & $0.987(0.966-1.009)$ & 0.232 \\
\hline \multirow[t]{3}{*}{ Physical Activity (\%) } & $\mathrm{H}$ & $78(56.5)$ & $58(42.0)$ & Reference & \\
\hline & $M$ & $25(18.1)$ & $27(19.6)$ & $1.324(0.688-2.545)$ & 0.401 \\
\hline & L & $35(25.4)$ & $53(38.4)$ & $2.253(1.283-3.957)$ & $0.005^{\star}$ \\
\hline \multirow[t]{2}{*}{ Vegetable intake (\%) } & $<500 \mathrm{~g} /$ day & $94(68.1)$ & $94(68.1)$ & $1.068(0.632-1.806)$ & 0.805 \\
\hline & $\begin{array}{l}\geq 500 \\
\text { g/day }\end{array}$ & 44 (31.9) & $44(31.9)$ & & \\
\hline \multirow[t]{2}{*}{ Fat intake (\%) } & $<50 \mathrm{~g} /$ day & $\begin{array}{l}107 \\
(77.5)\end{array}$ & $121(87.7)$ & $0.420(0.213-0.830)$ & $0.012 *$ \\
\hline & $\geq 50 \mathrm{~g} /$ day & $31(22.5)$ & $17(12.3)$ & & \\
\hline
\end{tabular}

Note: Logistic regression with method 'Enter' was applied for risk assessment in both model 1 and model 2. 40 husbands with abdominal obesity (AO) and their non-AO wives were included in model 1. And 138 wives with $\mathrm{AO}$ and their non-AO husbands was included in model 2. Abbreviations: $\mathrm{Cl}$, confidence interval; $O R$, odds ratio; $\mathrm{H}$, high physical activity; $\mathrm{M}$, medium physical activity; $\mathrm{L}$, low physical activity. ${ }^{*} P<0.05$. 


\section{Discussion}

The differences of heritable and environmental risk between male and female $\mathrm{AO}$ were investigated in this study. The prevalence of $A O$ was compared between the first-degree relatives of family-based study and people of the Henan Rural Cohort to assess the heritable risk, which was further determined in offspring. Then a couple case-control study was applied to assess the environmental risk. The results indicated that women were at a higher risk to develop $A O$ than men. Moreover, the risk could be transmitted from mother to daughter and even from grandmother to granddaughter. However, no significantly heritable risk of $\mathrm{AO}$ was observed from father to daughter or from grandfather to granddaughter. In addition, the results of couple case-control study indicated that low physical activity was a risk factor for women to develop AO. Therefore, women are heritably susceptible to AO, especially for those who have maternal family history. Increasing physical activity may protect them from suffering from $\mathrm{AO}$.

This study showed that women were more susceptible to AO, which was consistent with previous studies. A national study in China showed that the prevalence of $A O$ increased from $8.5 \%$ in 1993 to $27.8 \%$ in 2009 in men and from $27.8-45.9 \%$ in women.[16] A review of the dynamic trends in the prevalence of AO between 1989 and 2011 suggested that the prevalence of AO was higher in women than in men in all cycles.[17] This significant sex differences may be due to the homeostasis of endocrine regulation between men and women. After menopause, the secretion of sex hormones in women decreases, resulting in the accumulation of visceral fat and an increased risk of metabolic disorders. $[18,19]$ The alarming increase in the prevalence of $\mathrm{AO}$ may partly explain the increase in the prevalence of metabolic syndrome in recent years. It was reported that $\mathrm{AO}$ with normal BMI was associated with cardiovascular diseases, and was related to dyslipidemia in women.[20] Another South Korean study showed that general obesity without $\mathrm{AO}$ was not associated with a higher risk of cardiovascular diseases.[21]

Another major finding of this study was that women with maternal AO history have a higher risk of developing AO. This heritable risk included genetic and environmental factors as well as geneenvironmental interaction. However, it is difficult to completely separate the effects of gene and environment on AO, and gene-environment interaction plays an important role in this heritable risk. The important molecular mechanism of gene-environment interaction is epigenetics. For example, the heritability of BMI could be up to $70 \%$.[22] However, GWAS suggested that SNP contributed only $6 \%$ to BMI.[23] The unknown part of heritable contribution may be associated with epigenetic transmission. Recent work has indicated that DNA methylation, histone modification and other epigenetic changes played a vital role in fetal growth and development.[24, 25] An animal experiment showed that experiencing high-fat diet in womb may cause epigenetic changes and the metabolic disorders in offspring, suggesting that a mother's experience during pregnancy may cause epigenetic changes and be transmitted to the next generation.[26]

On the other hand, the epigenetic pattern associate with $A O$ may be reversible. The results of this study suggested that female offspring with $A O$ mother had higher risk to develop $A O$ than male offspring. This 
may be related to epigenetic changes caused by physical activity. Recent studies have shown that epigenetics is highly active and affected by environmental factors.[27] Previous study revealed that moderate exercise could up-regulate the methylation level of related proteins and contributed to reduce inflammation level, thus preventing the occurrence of diseases associated with chronic inflammation.[28] Some studies have shown that physical activity also plays a vital role in histone modification and noncoding RNA expression.[29, 30] Therefore, physical activity would regulate the epigenetic mechanisms of a variety of human diseases. Due to the traditional family division of labor in China, men are responsible for most of the outdoor work, which results in a significantly higher level of physical activity in men than in women. Increased physical activity in men may reverse the epigenetic changes associated with AO, which may be one reason to explain the higher risk of $\mathrm{AO}$ in women than in men.

Moreover, transmission of risk lifestyle for $\mathrm{AO}$ from mother or grandmother to offspring may be another factor to increase AO prevalence in AO families. Caregivers act as instructors and executors of children's behavior patterns in early childhood, affecting children's development and future lifestyles and habits of behavior.[31] It was reported that parents with $\mathrm{AO}$ had less physical activity and higher fat intake than normal parents, which also create an environment for their children to suffer from obesity.[32] Similarly, children with good household routines have a lower risk of obesity.[33] In China rural areas, it is common for men to go out for work, leaving their wives or mothers to take care of their children. With the rapid economic and social development, part of women living in rural area go out to work to reduce the financial burden. As a result, the grandmother is the primary caregiver of children. Grandmothers' low level of education and lack of health and nutrition knowledge would easily lead to overfeeding of children, which will have a negative impact on the formation of offspring's behavior patterns.[34] This process may be one reason to explain the transmission process of $A O$ risk behavior model from parent to offspring.

In addition, it was suggested that higher fat intake was significantly associated with AO for male, but a protective factor for female. It may be attributed to the fact that fat intake of males is higher than that of females in both cases and controls (Fig. 2).

This is an original study to integrate a family-based study and a cohort study with large sample in the same district. Thus, the results are reliable and convincing. Present study indicated that women with maternal $\mathrm{AO}$ history had a higher risk of developing $\mathrm{AO}$, which revealed information about sex differences in $\mathrm{AO}$ and had important public health implications. The results also provided clues for further study of the underlying mechanisms for sex differences in AO risk. On the other hand, limitations of this study must be acknowledged. First, the results would be more credible if the sample size of family-based study was larger. Nevertheless, unlike the recruitment of other cross-sectional subjects, family-based study required complete several generations, coupled with the older age of the target population, which greatly increased the difficulty of expanding the sample size. Therefore, polycentric and multi co-operational studies are needed to verify the conclusion of this study in the future. Then, this study did not separate genetic from environmental contributions to $A O$ risk, although this is not our general aim. Future work that focuses on the gene-environment interaction will be a good supplement of current research. More so, 
the generalizability of our results to the whole population may be uncertain, but it has good applicability to low and middle-income areas represented by rural areas.

\section{Conclusions}

In this study combined family-based study and case-control study found that females are heritably susceptible to AO, especially for those who have maternal family history. Increasing physical activity may protect them from suffering from AO. Proactive action based on maternal family history is a costeffective strategy for the prevention of $\mathrm{AO}$, although dim light was shed on the sex differences of heritable and environmental risk for $\mathrm{AO}$ and a larger family-based study is required to verify the conclusion.

\section{Abbreviations}

BMI: body mass index; AO: abdominal obesity; WC: waist circumference.

\section{Declarations}

\section{Ethics approval and consent to participate}

This study complied with the Declaration of Helsinki. The Life Science Ethics Review Committee of Zhengzhou University had reviewed and approved the protocol. All the subjects participated in this study had signed an informed consent.

\section{Consent for publication}

Written informed consent for publication was obtained from all participants.

\section{Availability of data and materials}

The data used during the current study are available from the corresponding author on reasonable request.

\section{Competing interests}

There was no conflict of interest to be declared.

\section{Funding}

This research was funded by the National Key Research and Development Program "Precision Medicine Initiative" of China (No. 2016YFC0900803), China Postdoctoral Science Foundation (No. 2020M672298) and the Key R\&D and Promotion Projects of Henan Province (192102210037).

\section{Authors' contributions}


SY designed the research, drafted the original manuscript, performed the statistical analysis. YF drafted the original manuscript, performed the statistical analysis. CQ analyzed and interpreted the data, revised the original manuscript. XL designed the research, revised the original manuscript. WH and ZM designed the research, analyzed and interpreted the data, revised the original manuscript. CC put forward conception, reviewed the manuscript. CW and WL designed the research, reviewed the manuscript, managed and coordinated the planning and execution of research activities and provided financial support for the study.

\section{Acknowledgements}

The authors thank all the colleague who participated in the family-based study and the Henan Rural Cohort Study. Thanks to all the patients who participated in this study.

\section{References}

1. Nurdiantami Y, Watanabe $K$, Tanaka E, et al. Association of general and central obesity with hypertension. Clin Nutr. 2018;37:1259-63.

2. Xue H, Wang C, Li Y, et al. Incidence of type 2 diabetes and number of events attributable to abdominal obesity in China: A cohort study. J Diabetes. 2016;8:190-8.

3. Zhang L, Wang Z, Wang X, et al. Prevalence of Abdominal Obesity in China: Results from a CrossSectional Study of Nearly Half a Million Participants. Obesity (Silver Spring). 2019;27:1898-905.

4. Paniagua L, Lohsoonthorn V, Lertmaharit S, et al. Comparison of Waist Circumference, Body Mass Index, Percent Body Fat and Other Measure of Adiposity in Identifying Cardiovascular Disease Risks among Thai Adults. Obes Res Clin Pract. 2008;2:215-23.

5. Nazare JA, Smith JD, Borel AL, et al. Ethnic influences on the relations between abdominal subcutaneous and visceral adiposity, liver fat, and cardiometabolic risk profile: the International Study of Prediction of Intra-Abdominal Adiposity and Its Relationship With Cardiometabolic Risk/Intra-Abdominal Adiposity. Am J Clin Nutr. 2012;96:714-26.

6. Caspard H, Jabbour S, Hammar N, et al. Recent trends in the prevalence of type 2 diabetes and the association with abdominal obesity lead to growing health disparities in the USA: An analysis of the NHANES surveys from 1999 to 2014. Diabetes Obes Metab. 2018;20:667-71.

7. Garcia-Hermoso A, Martinez-Vizcaino V, Recio-Rodriguez JI, et al. Abdominal obesity as a mediator of the influence of physical activity on insulin resistance in Spanish adults. PREV MED. 2016;82:59-64.

8. Lim S, Shin $\mathrm{H}$, Song JH, et al. Increasing prevalence of metabolic syndrome in Korea: the Korean National Health and Nutrition Examination Survey for 1998-2007. Diabetes Care. 2011;34:1323-8.

9. Zhang X, Shu XO, Gao YT, et al. General and abdominal adiposity and risk of stroke in Chinese women. Stroke. 2009;40:1098-104.

10. Beardsall K, Ong KK, Murphy N, et al. Heritability of childhood weight gain from birth and risk markers for adult metabolic disease in prepubertal twins. J Clin Endocrinol Metab. 2009;94:3708-13. 
11. Luo BF, Du L, Li JX, et al. Heritability of metabolic syndrome traits among healthy younger adults: a population based study in China. J Med Genet. 2010;47:415-20.

12. Li JK, Ng MC, So WY, et al. Phenotypic and genetic clustering of diabetes and metabolic syndrome in Chinese families with type 2 diabetes mellitus. Diabetes Metab Res Rev. 2006;22:46-52.

13. Hu Z, Tao S, Liu H, et al. The Association between Polymorphisms of Vitamin D Metabolic-Related Genes and Vitamin D3 Supplementation in Type 2 Diabetic Patients. J Diabetes Res. 2019;2019:8289741.

14. Zhou BF, Cooperative Meta-Analysis Group of the Working Group on Obesity in C Predictive values of body mass index and waist circumference for risk factors of certain related diseases in Chinese adults-study on optimal cut-off points of body mass index and waist circumference in Chinese adults. Biomed Environ Sci. 2002;15:83-96.

15. National Institute for Nutrition and Health of Chinese Center for Disease Control and Prevention. Chinese Food Composition Table (Standard Edition), Peking University Medical Press: Beijing, China, 2018

16. Xi B, Liang Y, He T, et al. Secular trends in the prevalence of general and abdominal obesity among Chinese adults, 1993-2009. Obes Rev. 2012;13:287-96.

17. Chen Y, Peng Q, Yang Y, et al. The prevalence and increasing trends of overweight, general obesity, and abdominal obesity among Chinese adults: a repeated cross-sectional study. BMC Public Health. 2019;19:1293.

18. Tramunt B, Smati S, Grandgeorge N, et al. Sex differences in metabolic regulation and diabetes susceptibility. Diabetologia. 2020;63:453-61.

19. Liu P, Ji Y, Yuen T, et al. Blocking FSH induces thermogenic adipose tissue and reduces body fat. Nature. 2017;546:107-12.

20. Kim HY, Kim JK, Shin GG, et al. Association between Abdominal Obesity and Cardiovascular Risk Factors in Adults with Normal Body Mass Index: Based on the Sixth Korea National Health and Nutrition Examination Survey. J Obes Metab Syndr. 2019;28:262-70.

21. Choi D, Choi S, Son JS, et al. Impact of Discrepancies in General and Abdominal Obesity on Major Adverse Cardiac Events. J Am Heart Assoc. 2019;8:e013471.

22. Stunkard AJ, Harris JR, Pedersen NL, et al. The body-mass index of twins who have been reared apart. N Engl J Med. 1990;322:1483-7.

23. Yengo L, Sidorenko J, Kemper KE, et al. Meta-analysis of genome-wide association studies for height and body mass index in approximately 700000 individuals of European ancestry. Hum Mol Genet. 2018;27:3641-9.

24. Kitsiou-Tzeli S, Tzetis M Maternal epigenetics and fetal and neonatal growth. Curr Opin Endocrinol Diabetes Obes. 2017;24:43-6.

25. Tekola-Ayele F, Workalemahu T, Gorfu G, et al. Sex differences in the associations of placental epigenetic aging with fetal growth. Aging (Albany NY). 2019;11:5412-32. 
26. Masuyama H, Mitsui T, Nobumoto E, et al. The Effects of High-Fat Diet Exposure In Utero on the Obesogenic and Diabetogenic Traits Through Epigenetic Changes in Adiponectin and Leptin Gene Expression for Multiple Generations in Female Mice. Endocrinology. 2015;156:2482-91.

27. Cavalli G, Heard E Advances in epigenetics link genetics to the environment and disease. Nature. 2019;571:489-99.

28. Lavie CJ, Church TS, Milani RV, et al. Impact of physical activity, cardiorespiratory fitness, and exercise training on markers of inflammation. J Cardiopulm Rehabil Prev. 2011;31:137-45.

29. Widmann M, Niess AM, Munz B Physical Exercise and Epigenetic Modifications in Skeletal Muscle. Sports Med. 2019;49:509-23.

30. Badon SE, Littman AJ, Chan KCG, et al. Physical activity and epigenetic biomarkers in maternal blood during pregnancy. Epigenomics. 2018;10:1383-95.

31. Muthuri SK, Onywera VO, Tremblay MS, et al. Relationships between Parental Education and Overweight with Childhood Overweight and Physical Activity in 9-11 Year Old Children: Results from a 12-Country Study. PLoS One. 2016;11:e0147746.

32. Tu AW, Watts AW, Masse LC Parent-Adolescent Patterns of Physical Activity, Sedentary Behaviors and Sleep Among a Sample of Overweight and Obese Adolescents. J Phys Act Health. 2015;12:1469-76.

33. Anderson SE, Whitaker RC Household Routines and Obesity in US Preschool-Aged Children. Pediatrics. 2010;125:420-8.

34. Trivedi T, Liu J, Probst J, et al. Obesity and obesity-related behaviors among rural and urban adults in the USA. RURAL AND REMOTE HEALTH. 2015;15:3267.

\section{Figures}




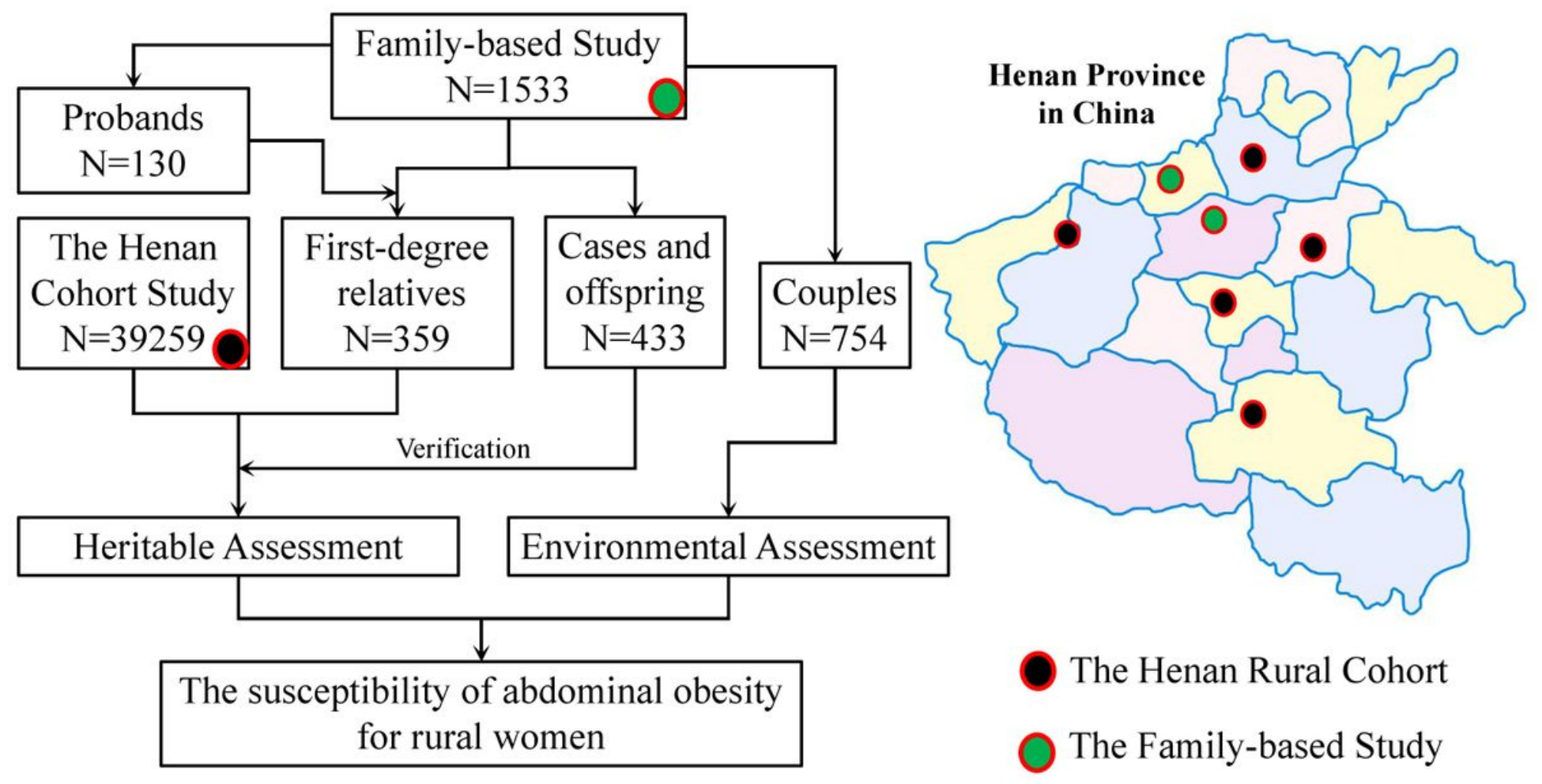

\section{Figure 1}

Family-based study were carried out in Henan Rural areas, China. Comparing with the AO prevalence in Henan Rural Cohort study, the AO prevalence among the first-degree relatives of probands were applied to assess the heritable impact. The comparison of the prevalence of male and female offspring of $A O$ provided further evidence. On the other hand, case-control couples were employed to investigate the sex differences of environmental risk factors of AO. Note: The designations employed and the presentation of the material on this map do not imply the expression of any opinion whatsoever on the part of Research Square concerning the legal status of any country, territory, city or area or of its authorities, or concerning the delimitation of its frontiers or boundaries. This map has been provided by the authors. 


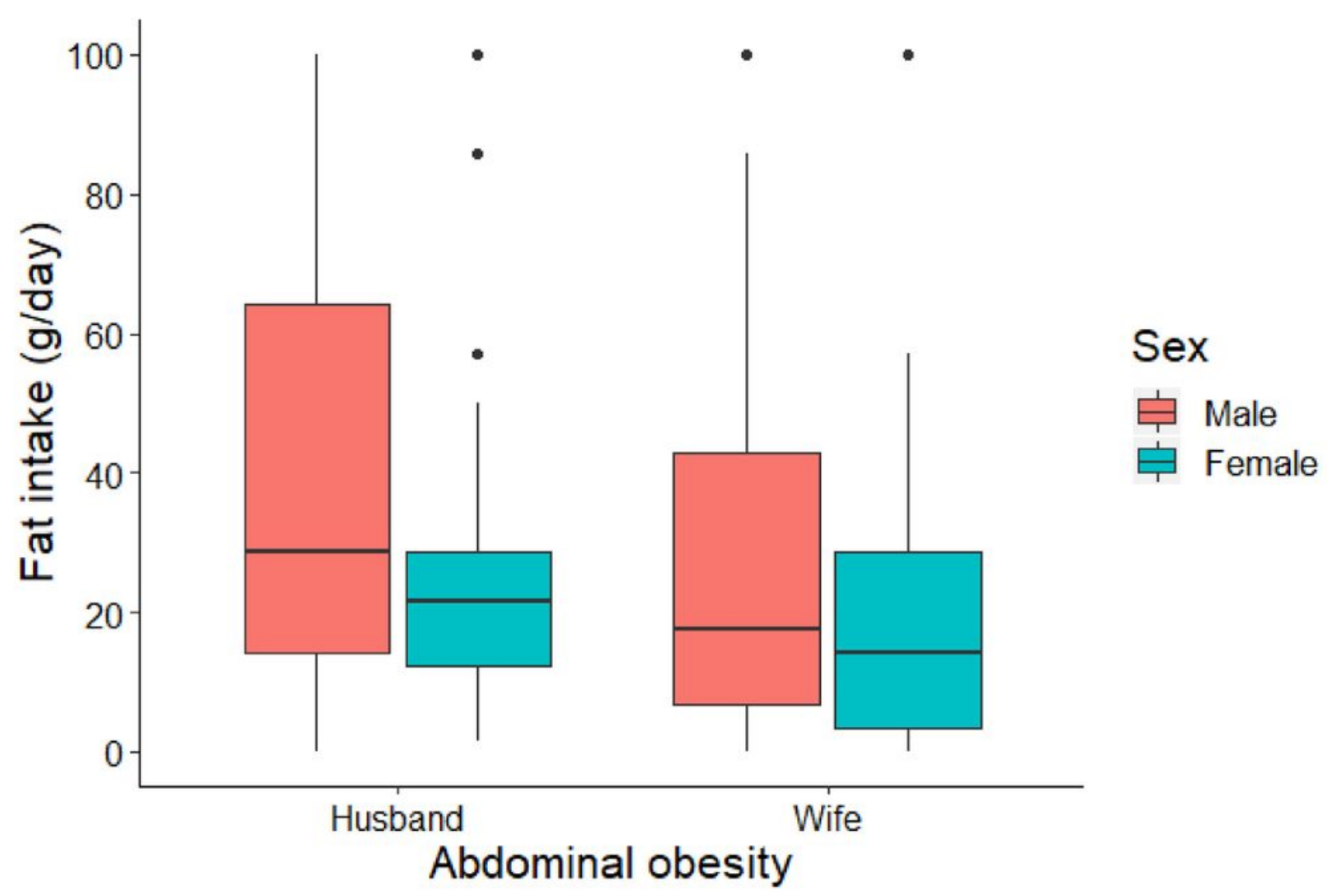

Figure 2

Fat intake in case-control couples with one partner with AO. Husbands had higher fat intake than wives.

\section{Supplementary Files}

This is a list of supplementary files associated with this preprint. Click to download.

- GraphicalAbstract.jpg 